\title{
THE LUMINESCENCE OF SOLID BIS(2,9-DIPHENYL-1,10-PHENANTHROLINE) COPPER(I)
}

\author{
G.BLASSE, P.A. BREDDELS * \\ Physical Laboratory. State University Utrecht, P.O.Box 80.000, 3508 TA Utrecht, The Netherlands \\ and \\ D.R. MCNILLIN \\ Department of Chemistry, Purdue University. West Lafoyette, Indiana 47 yo7, USA
}

Recoived 10 April 1984

\begin{abstract}
The luminescence of the litle complex $\left[\mathrm{Cu}(\mathrm{dpp})_{2}\right]^{+}$in the solid state is reported. The results are compared with those
\end{abstract} of related $\mathrm{Cu}^{+}$complexes and with those for $\left[\mathrm{Cu}(\mathrm{dpp})_{2}\right]^{+}$in solution.

\section{Introduction}

The luminescence of $\mathrm{Cu}(\mathrm{I})$ complexes has been the subject of investigation for some time. Isolated complexes have been investigated in glasses or in solution $[1-4]$, but the luminescence of solid complexes has also been reported $[5,6]$. The emission originates from low-lying metal-tu-ligand charge-transfer (MLCT) excited states. These complexes can also be used as sensitizers of wide-band-gap semiconductors [7.8].

In $\left[\mathrm{Cu}(\mathrm{dpp})_{2}\right]^{+}$the bulky ligands protect the metal center from its environment, i.e. the molecules of the solvent. This leads to a marked increase of the luminescence intensity in comparison with, e.g. $\left[\mathrm{Cu}(\mathrm{dmp})_{2}\right]^{+}[4]$. Such an effect should play no role in the solid state. The luminescence of solid $\left[\mathrm{Cu}\left(\mathrm{d}_{\mathrm{pp}}\right)_{2}\right]^{+}$is expected to be in line with the other $\mathrm{Cu}^{+}$complexes. This hypothesis initiated the present investigation.

\section{Experimental}

The preparation of $\left[\mathrm{Cu}(\mathrm{dpp})_{2}\right]^{+} \cdot \mathrm{BF}_{4}^{-}$was carried uut as described in ref. [4]. The way in which the op-

\footnotetext{
* Present address: Philips Research Laboratorjes, 5600JA Eindhoven. The Netherlands.
}

tical measurcments were performed has been reported in ref. [6].

\section{Results}

The complex $\left[\mathrm{Cu}(\mathrm{dpp})_{2}\right]^{+} \cdot \mathrm{BF}_{4}^{-}$in the solid state shows only a very weak, deep-red emision. The quantum efficiency at room temperature is lower than 0.01 . The emission consists of a broad band with a maximum at about $710 \mathrm{~nm}$. An emission spectrum is given in fig. 1 .

At $4.2 \mathrm{~K}$ the position of the emission maximum is at about the same wavelength. The emission intensity at $4.2 \mathrm{~K}$ is only slightly higher than at room temperature, but there is a shallow minimum at about $200 \mathrm{~K}$. This is very similar to what has been reported for the other $\mathrm{Cu}^{+}$complexes [6].

In table 1 the Iuminescence properties of the different $\mathrm{Cu}^{+}$complexes in the solid state are compared (data from refs. $[1-6]$ ). For this purpose we measured the decay time of the luminescence of $\left[\mathrm{Cu}(\mathrm{dmp})_{2}\right]^{+}$. $\mathrm{BF}_{4}$ at $4.2 \mathrm{~K}$. The decay curve is exponential and yields a decay time of $3.2 \mu \mathrm{s}$. At $300 \mathrm{~K}$ the emission is too weak to allow decay-time measurements with the apparatus at our disposal. The same is true for $\left[\mathrm{Cu}(\mathrm{dpp})_{2}\right]^{+} \cdot \mathrm{BF}_{4}^{-}$at all temperatures. (North-Holland Physics Publishing Division) 


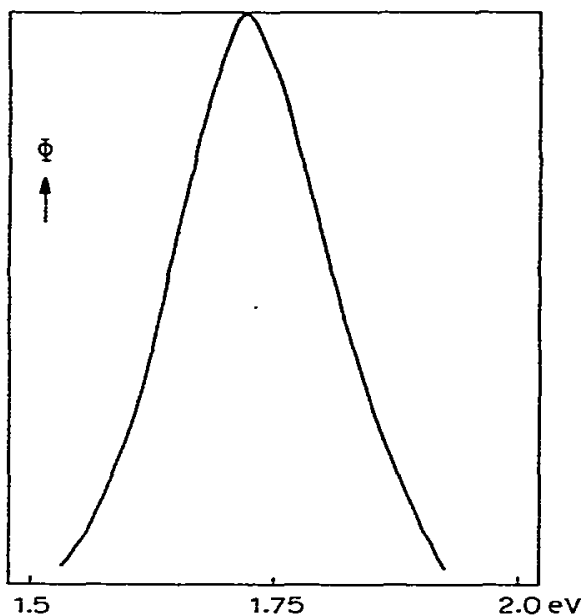

Fig. 1. Emission spectrum of solid $\left[\mathrm{Cu}(\mathrm{dpp})_{2}\right]^{+} \cdot\left[\mathrm{BF}_{4}\right]^{-}$at $300 \mathrm{~K}$. $\Phi$ gives the spectral radiant power per constant energy interval in arbitrary units.

\section{Discussion}

In table 1 the $\mathrm{Cu}^{+}$complexes are arranged in sequence of increasing emission wavelength maximum, i.e. from top to bottom the MLCT transition energy decreases. Simultaneously the quantum efficiency at $300 \mathrm{~K}$ decreases. This is due to the fact that the probability for non-radiative transitions increases if the (broad-band) MLCT transition shifts to lower energy
[9]. The decrease of the decay times is related to the increase of the non-radiative transition probability [6]. No luminescence was observed for the $\left[\mathrm{Cu}\left(\mathrm{biq}_{2}\right]^{+}\right.$ complex. This is in line with the outspoken longwavelength position of the absorption band, i.e. the MLCT transition. From these data we conclude that the luminescence properties of the $\left[\mathrm{Cu}(\mathrm{dpp})_{2}\right]^{+} \mathrm{com}-$ plex in the solid state are well in line with those of the other complexes in the solid state.

For the complexes in solution the situation is different, because $\left[\mathrm{Cu}(\mathrm{dpp})_{2}\right]^{+}$in solution luminesces more efficiently than [Cu(dmp $\left.)_{2}\right]^{*}$ in solution [4]. The present results confirm the hypothesis put forward elsewhere [4], viz. the four phenyl rings around the copper centre protect the complex from external molecules. In this way they reduce the non-radiative transition probability. In the solid state this effect has no influence on the non-radiative transitions.

These complexes can be applied as sensitizers of wide-band-gap semiconductors [7]. We have found the highest quantum efficiencies for photocurrent generation for the $\mathrm{Cu}^{+}$complexes with the highest MLCT transition energy. It was found, however, that $\left[\mathrm{Cu}(\mathrm{dpp})_{2}\right]^{+}$sensitizes more efficiently than $\left[\mathrm{Cu}(\mathrm{dmp})_{2}\right]^{+}$in spite of the longer-wavelength emission of the former [8]. This result may suggest that other factors are important in addition to the excitedstate lifetime.

Table 1

Luminescence propertics of $\mathrm{Cu}^{+}$complexes

\begin{tabular}{|c|c|c|c|c|c|c|c|}
\hline \multirow[t]{2}{*}{$\begin{array}{l}\text { Complex } \\
\text { ion i) }\end{array}$} & \multirow{2}{*}{$\begin{array}{l}\text { Color of } \\
\text { the solid } \\
\text { coniplex }\end{array}$} & \multirow{2}{*}{$\begin{array}{l}\text { Absorption } \\
\text { maximum (nm) } \\
\text { in solution }\end{array}$} & \multicolumn{2}{|c|}{$\begin{array}{l}\text { Emission } \\
\text { maximum (nm) }\end{array}$} & \multirow{2}{*}{$\begin{array}{l}\text { Quantum } \\
\text { efficiency } \\
\text { at } 300 \mathrm{~K}\end{array}$} & \multicolumn{2}{|c|}{$\begin{array}{l}\text { Decay time } \\
(\mu s)\end{array}$} \\
\hline & & & $4.2 \mathrm{~K}$ & $300 \mathrm{~K}$ & & $4.2 \mathrm{~K}$ & $300 \mathrm{~K}$ \\
\hline $\mathrm{Cu}\left(\mathrm{PPh}_{3}\right)_{2}$ phen ${ }^{+}$ & yellow & 365 & 535 & 515 & 0.75 & 250 & 30 \\
\hline $\mathrm{Cu}\left(\mathrm{PPh}_{3}\right)_{2} \mathrm{dmp}^{+}$ & yellow & 365 & 530 & 515 & 0.75 & 250 & 30 \\
\hline $\mathrm{Cu}\left(\mathrm{PPh}_{2} \mathrm{CH}_{3}\right)_{2} \mathrm{dmp}{ }^{+}$ & yellow & 365 & 560 & 525 & 0.75 & 250 & 30 \\
\hline $\mathrm{Cu}\left(\mathrm{PPh}_{3}\right)_{2} \mathrm{bpy}^{+}$ & yellow & 356 & 585 & 560 & 0.15 & 30 & 7 \\
\hline $\mathrm{Cu}\left(\mathrm{PPh}_{3}\right)_{2} \mathrm{biq}^{+}$ & orange & 415 & 630 & 605 & 0.17 & 30 & 7 \\
\hline $\mathrm{Cu}(\mathrm{dmp})_{2}$ & red & 454 & 680 & 650 & $\approx 0.01$ & 3 & - \\
\hline $\mathrm{Cu}(\mathrm{dpp})_{2}^{+}$ & deepred & 439 & $\approx 710$ & $\approx 710$ & $<0.01$ & - & - \\
\hline $\mathrm{Cu}(\mathrm{biq})_{2}^{+}$ & black & 545 & - & - & “o" & - & - \\
\hline
\end{tabular}

a) $\mathrm{PPh}_{3}$ : triphenylphosphine; phen: 1,10-phenanthroline; dmp: 2,9-dimethyl-1,10-phenanthroline: $\mathrm{PPh}_{2}^{2} \mathrm{CH}_{3}:$ methyldiphenylphosphine; bpy: 2,2'-bipyridine; biq: 2,2'-biquinoline; dpp: 2,9-diphenyl-1,10-phenanthroline. 


\section{Acknowledgement}

These investigations were carried out as part of the research programme of the "Foundation for Fundamental Research on Matter" (FOM) with financial suppo:t of the "Foundation for Technical Research" (STW). This work was also supported by NATO Research Grant No. 062.82.

\section{References}

11] M.T. Buckner and D.R. McMillin, J. Chem. Soc. Chem. Cominun (1978) 759.

[2] M.T. Buckner, T.G. M.tthews, F.E. Lytle and D.R. Mc.lillin, J. Am. Chem. Soc. 101 (1979) 5846.

[3] M.W. Blaskie and J.R. McMillin, Inorg. Chem. 19 (1980) 3519.
[4] C.O. Dietrich-Buchecker, P.A. Marnot, J.P. Sauvage, J.R. Kirchhoff and D.R. McMillin, J. Chem. Soc. Chem. Commun. (1983) 513.

[5i G. Blasse and D.R. McMillin, Chem. Phys. Letters 70 (1980) 1.

[6] P.A. Breddels, P.A.M. Berdowski, G. Blasse and D.R. McMillin, J. Chem. Soc. Faraday Trans. II 78 (1982) 595.

[7] P.A. Breddels, G. Blasse, D.J. Casadonte and D.R. MicMillin, Ber. Bunsenges. Physik. Cliem., to be published; P.A. Breddels, Thesis, Utrecht (1983) (available upon request).

[8] N. Alonso Vante, V. Ern, P. Chartier, C.O. DietrichBuchecker, D.R. McMillin, P.A. Marnot and J.P. Sauvage, Nouv. J. Chim. 7 (1983) 3.

[9] K.C. Bleijenberg and G. Blasse, J. Solid State Chern. 28 (1979) 303. 